\title{
ANÁLISE DA COMPOSIĈ̃O DAS RECEITAS DOS MUNICÍPIOS LINDEIROS AO LAGO DA ITAIPU BINACIONAL NO ESTADO DO PARANÁ
}

\author{
Sofia Carline Dressel ${ }^{1}$ \\ Loreni Maria dos Santos Braum²
}

\section{RESUMO}

O objetivo desta pesquisa é analisar a composição das receitas e despesas dos municípios paranaenses lindeiros ao lago de Itaipu, a fim de verificar o possível impacto que possa ocorrer no orçamento destes municípios a partir do ano em que deixarem de receber os royalties da Itaipu Binacional. A metodologia caracteriza-se como um estudo multicasos, utilizando-se da pesquisa bibliográfica e documental, sendo um estudo exploratório com abordagens quantitativas e qualitativas. A fundamentação teórica trata de assuntos pertinentes a análise das finanças dos municípios lindeiros. Quanto aos resultados, identificou-se que, quanto maior a área atingida, maior é o recebimento de royalties. Proporcionalmente ao total de arrecadação, para alguns municípios as compensações financeiras corresponderam a uma fatia maior de recursos do que para outros. Enquanto há municípios que recebem poucos royalties e investem muito em infraestrutura, há outros que recebem mais, mas investem pouco nestas ações. Concluiu-se que os impactos serão sentidos de formas diferenciadas em cada um dos municípios. O tempo de recebimento destes recursos, até a revisão do tratado de Itaipu, é curto, sendo necessários investimentos em setores que tragam, de formas diferenciadas, mais recursos financeiros e aprimorem o desenvolvimento econômico e social.

PALAVRAS-CHAVE: IMPACTO. ROYALTIES. MUNICÍPIOS LINDEIROS.

\footnotetext{
${ }^{1}$ Centro Universitário Internacional UNINTER.

2 Mestre em Ciências Contábeis (FURB). Especialista em Administração Financeira Contábil e Controladoria (INBRAPE). Especialista em Docência no Ensino Superior (UNIPAN). Graduada em Ciências Contábeis (UNIVEL). Docente na Universidade Estadual do Oeste do Paraná - UNIOESTE.
} 


\section{INTRODUÇÃO}

Conforme informações disponibilizadas no site da Itaipu Binacional (2012a), após a construção da barragem da Hidrelétrica de Itaipu no Rio Paraná, tanto o governo do Brasil quanto do Paraguai passaram a receber mensalmente, a partir de 1985, uma compensação financeira, denominada royalties. Este recurso é destinado a compensar os prejuízos econômicos causados pela inundação da grande área às margens do lago que deixaram de ser produtivas. De acordo com o Anexo $\mathrm{C}$ do Tratado de Itaipu, os royalties serão distribuídos até abril de 2023 (ITAIPU BINACIONAL, 2012b).

No Brasil, os royalties são repassados ao Tesouro Nacional e distribuídos, desde 1991 , da seguinte forma: $45 \%$ dos recursos para os municípios, $45 \%$ para os estados e 10\% para os órgãos federais, sendo estes: Ministério do Meio Ambiente, Ministério de Minas e Energia e Fundo Nacional de Desenvolvimento Científico e Tecnológico - FNDCT (ITAIPU BINACIONAL, 2012a).

Dos $45 \%$ municipais e $45 \%$ estaduais, $85 \%$ são destinados aos municípios e estados diretamente atingidos, denominados lindeiros e 15\% aos indiretamente atingidos, localizados a montante (acima) da Usina de Itaipu (BRASIL, Lei 9.984/2000, 2012e, art. 1 e 3).

O rateio do recurso entre os municípios lindeiros é determinado segundo o ganho da geração de energia, pela vazão e principalmente em virtude da área inundada pelo Lago de Itaipu, variando mensalmente conforme a geração total de energia (ITAIPU BINACIONAL, 2012a). Assim, quanto maior a área inundada maior é o valor de royalties recebido pelo município.

Conforme Iwake (2005, p. 25), os royalties de Itaipu deixam os municípios lindeiros entre os "detentores dos orçamentos mais ricos do Paraná". Destaca ainda, que estes recursos possibilitam aos gestores realizarem 'quase tudo' que almejam.

Segundo Oliveira (2008, p. 230), "é notória a importância conferida aos recursos dos royalties para os municípios Lindeiros.". O autor destaca que estes recursos não se limitam apenas aos serviços públicos essenciais, como educação, 
saúde, infraestrutura, etc., mas principalmente, possibilitam um fortalecimento na economia. Contudo, ressalta que muitos dos municípios lindeiros tornaram-se dependentes dos royalties e a extinção dos repasses afetaria os setores público e privado, pois estes recursos "são perniciosos à solidez da economia, pela forma como vêm sendo despendidos" (OLIVEIRA 2008, p. 232).

Para Silva, (2007, p. 132) dentre os municípios que recebem Compensação Financeira e que "apresentaram os maiores crescimentos nos indicadores sociais e econômicos destacam-se aqueles que mais destinam parte de sua receita à realização de investimentos em infraestrutura". Porém, Oliveira (2008) destaca que a destinação de royalties em grandes infraestruturas podem ser ameaçadores, devido à dificuldade de manutenção.

Estudos realizados por Oliveira (2008), Sterchile e Souza (2008), Iwake (2005) e Bem e Batti (2003) concluíram que os municípios lindeiros tornaram-se dependentes dos royalties e que as dificuldades econômicas e sociais são frutos da má gestão destes recursos. Portanto há muito ainda a ser feito para concretizar o desenvolvimento socioeconômico sustentável.

Considerando as receitas das compensações financeiras importantes para os municípios lindeiros, e o corte dos repasses a partir de maio de 2023, surge a necessidade de verificar a situação financeira de cada um deles, através da análise da composição das receitas e despesas.

Assim, este estudo se concentrou em torno da seguinte questão: Qual será o impacto ocasionado nos orçamentos dos municípios lindeiros a partir do momento em que deixarem de receber os royalties da Itaipu?

O objetivo desta pesquisa é analisar a composição das receitas e despesas dos municípios paranaenses lindeiros ao lago de Itaipu, a fim de verificar o possível impacto que possa ocasionar no orçamento destes municípios a partir do ano em que deixarem de receber os royalties da Itaipu Binacional.

Esta pesquisa justifica-se pelo fato de que para os municípios lindeiros os royalties de Itaipu são extremamente importantes para o desenvolvimento 
econômico e social. O corte no repasse destes recursos poderá ser agravante nos municípios que não estiverem preparados.

Assim, levantar dados sobre a execução orçamentária nos municípios lindeiros e analisar o impacto que ocorrerá caso os royalties não sejam mais repassados, é importante para que as administrações públicas possam aplicá-los da melhor maneira, de forma que não impacte bruscamente em seu desenvolvimento econômico e social.

\section{FUNDAMENTAÇÃO TEÓRICA}

Neste tópico é apresentada a fundamentação teórica pertinente ao tema.

\subsection{Administração pública}

A Administração Pública é a "atividade concreta do Estado dirigida à consecução das necessidades coletivas de modo direto e imediato" (JUND, 2008, p. 28). É constituída por administrações diretas e indiretas. Compreendem as administrações diretas os poderes Legislativo, Executivo e Judiciário. Já as administrações indiretas são constituídas de entidades públicas com personalidade jurídica própria como autarquias, fundações, empresas públicas e sociedades de economia mista, que se vinculam às administrações diretas através de Lei (ARAÚJO; ARRUDA, 2004).

Neste contexto, a contabilidade apresenta-se como fornecedora de informações para subsidiar as decisões dos gestores públicos, órgãos de controles internos e externos (BEZERRA FILHO, 2008).

\subsection{Contabilidade pública}

A Contabilidade Pública é regulamentada pela Lei $\mathrm{n}^{0}$ 4.320/64 e pela Lei Complementar no 101/2000 - Lei de Responsabilidade Fiscal (LRF), assim como 
pela Constituição Federal de 1988 (CF/88), além de Normas Brasileiras de Contabilidade. É o ramo da ciência contábil que aplica as técnicas de registros e avaliações contábeis na Administração Pública de acordo com as normas legais (JUND, 2008).

A finalidade da Contabilidade Pública segundo Bezerra Filho (2008) é o de fornecer dados sobre a organização e execução dos orçamentos, normas para o registro das entradas de receitas e desembolsos de despesas, registro, controle e acompanhamento das variações patrimoniais, dentre outros.

Todos os órgãos da administração pública são obrigados, conforme o art. 52 da Lei Complementar 101 (BRASIL, 2012d), a publicarem até trinta dias antes do encerramento de cada bimestre o Relatório Resumido da Execução Orçamentária (RREO). Este é composto do balanço orçamentário e dos demonstrativos da execução das receitas e despesas, além de diversos relatórios anexos.

\subsection{Execução orçamentária e financeira}

A execução orçamentária e financeira, uma das etapas do ciclo orçamentário, incide na efetiva arrecadação das receitas e na realização das despesas. A execução orçamentária, conforme Jund (2008, p. 407), consiste "da fase de execução da despesa, devendo observar a Lei Orçamentária Anual e consistindo das etapas de empenho, liquidação e pagamento".

Já a execução financeira, segundo o mesmo autor, consiste em "arrecadar os recursos estimados, a fim de suprir o Tesouro para honrar os gastos relativos à execução da despesa por meio dos pagamentos realizados".

\subsubsection{Receitas}

Andrade (2002, p. 61) define a receita pública como sendo: 
virtude de leis, contratos, convênios e quaisquer outros títulos de que seja oriundo de alguma finalidade específica, cuja arrecadação lhe pertença ou figure como depositário dos valores que não Ihe pertençam.

As receitas orçamentárias são classificadas, segundo a categoria econômica, em Receitas Correntes e Receitas de Capital, conforme o artigo 9ำ da Lei 4.320/64 (BRASIL, 2012a).

As receitas correntes, segundo Jund (2008, p. 157), são os recursos "[...] recebidos de pessoas de direito público ou privado, destinado aos gastos correntes ou de consumo, obtidos nas transações efetivadas pelas entidades da Administração Pública que não resultem em 'sacrifício patrimonial'.". São classificadas, conforme a origem dos recursos, em receitas tributárias, de contribuição, patrimonial, agropecuárias, industriais, de serviços, transferências correntes e outras receitas correntes.

As receitas de capital, de acordo com Andrade (2002, p. 64), "são as receitas que se destinam à cobertura de despesas de capital a título de investimentos, com intitulação legal, e decorrem de um fato permutativo, ou seja, que cria acréscimo ao patrimônio público". Estas são classificadas em operações de crédito, alienação de bens, amortização de empréstimos, transferências de capital e outras receitas de capital.

\subsubsection{Despesas}

A Despesa Pública "é constituída pela obrigação de desembolso financeiro por parte dos cofres do Estado, objetivando financiar as ações do governo, bem como cumprir outras determinações impostas por leis, contratos, convênios" (BEZERRA FILHO, 2008, p. 81).

As despesas são classificadas em despesas correntes e despesas de capital. As despesas correntes correspondem as "destinadas à manutenção e ao funcionamento dos serviços públicos prestados pela própria Administração ou transferidos a outras pessoas físicas ou jurídicas." (JUND, 2008, p. 203), de forma que não aumentam o patrimônio da entidade. 
As despesas de capital, ao contrário das despesas correntes, são aquelas que, segundo Bezerra Filho (2008, p. 93) "contribuem, diretamente, para a formação ou aquisição de um bem de capital, resultando no acréscimo do patrimônio do órgão ou entidade que a realiza, aumentando, dessa forma, sua riqueza patrimonial.”.

\section{MÉTODO DE PESQUISA}

A pesquisa realizada caracteriza-se quanto aos objetivos como exploratória, pois se trata de estudo sobre um tema pouco explorado, que necessita ser aprofundado (RAUPP; BEUREN, 2010).

Quanto aos procedimentos, são utilizadas as pesquisas bibliográfica e documental, devido à utilização dos relatórios e documentos contábeis, disponíveis no site do Tesouro Nacional (2012), apoiados em bibliografias.

Danton (2002, p. 10) descreve que "A pesquisa bibliográfica deve anteceder todos os tipos de pesquisa." Pois, ela permite saber em qual estado determinado assunto se encontra.

Conforme Beuren (2010) a pesquisa bibliográfica tem o objetivo de recolher informações e conhecimentos que já foram publicados, buscando-se assim encontrar uma resposta. Sendo que por ser teórica, é parte fundamental, pois permite o conhecimento sobre a produção científica já existente sobre o assunto.

Dessa forma, a pesquisa bibliográfica diferencia-se da documental, pois essa se utiliza de materiais que ainda não receberam uma análise, ou ainda, que podem receber uma nova análise de acordo com o que a pesquisa objetiva responder.

No entanto a pesquisa documental ou de fontes primárias "é a que trabalha com informações que não receberam tratamento analítico." (BEUREN, 2010, p. 134). Sabendo-se que essas informações podem ser encontradas das mais diversas formas e ainda não foram analisadas, esta pesquisa quanto aos procedimentos caracteriza-se por ser documental.

Esta pesquisa também é caracterizada como um estudo multicaso, pela análise conjunta de vários municípios com um mesmo perfil. 
A abordagem do problema caracteriza-se como qualitativa e quantitativa, pois são identificadas as composições das receitas e despesas relacionadas com a aplicação.

De acordo com Richardson (1999, p. 70 apud Beuren, 2010, p. 92) a pesquisa quantitativa "caracteriza-se pelo emprego de quantificação tanto nas modalidades de coleta de informações, quanto no tratamento delas por meio de técnicas estatísticas $[\ldots] "$

Esse tipo de procedimento, de acordo com Beuren (2010), visa evitar distorção na análise dos dados, garantindo uma maior precisão nos resultados. Essa metodologia é aplicada quando se procura descobrir e classificar a relação entre as variáveis e os fenômenos.

Foi utilizado o procedimentos de pesquisa multicaso o qual, segundo Yin, 2001, proporcion maior abrangência dos resultados, não se limitando às informações de um só município.

A pesquisa também é considerada qualitativa, e conforme Richardson (1999, p. 80 apud Beuren, 2010, p. 91) pode ser descrita por "[...] descrever a complexidade de determinado problema, analisar a interação de certas variáveis, compreender e classificar processos dinâmicos vividos por grupos sociais.", além de "contribuir no processo de mudança de determinado grupo e possibilitar, em maior nível de profundidade, 0 entendimento das particularidades do comportamento dos indivíduos.".

\section{Análise dos Resultados}

Após a apresentação do embasamento teórico desta pesquisa, será apresentado a seguir um breve histórico da formação da Itaipu Binacional e os municípios abrangidos, bem como a análise das finanças destes municípios paranaenses, partindo-se dos relatórios resumidos da execução orçamentária do exercício de 2011. 


\subsection{A Itaipu Binacional e as compensações financeiras}

Conforme informação disponível no site da Itaipu Binacional (2012c), desde o século XVIII, Brasil e Paraguai disputavam a posse de terras da região do Salto de Sete Quedas. O Tratado da Permuta assinado em 1750 entre Espanha e Portugal, descrevia a fronteira entre os dois países, porém era impreciso na determinação exata dos "limites entre os territórios na margem direita do Rio Paraná, [...] cuja foz não se sabia ao certo se estava acima ou abaixo das Sete Quedas" (ITAIPU BINACIONAL, 2012c).

A perduração da imprecisão entre a determinação exata das fronteiras ocasionou a Guerra do Paraguai entre os anos de 1865 e 1870, que foi esclarecida com o Tratado de Paz no ano de 1872, o qual determinava que "[...] os territórios deveriam dividir-se pelo Rio Paraná, até o Salto, e pelo cume da Serra de Maracaju.". Porém o tratado teve interpretações divergentes devido a Serra dividir-se em dois ramos, acima e abaixo das Sete Quedas, ocasionando novamente um desacordo entre as partes (Idem, 2012c).

Em meados de 1960 a descoberta do potencial hidrelétrico do Rio Paraná fez com que Brasil e Paraguai novamente disputassem as Sete Quedas. Mas desta vez, ao invés de lutarem, os dois países uniram suas forças na produção de energia em conjunto. Vários estudos foram realizados para avaliação do potencial energético das Sete Quedas, porém nenhum projeto foi levado adiante. (ITAIPU BINACIONAL, 2012c).

O deslocamento de um destacamento militar brasileiro para a área de fronteira em 1965 reabriu um impasse diplomático entre os dois países, surgindo a ameaça de uma possível guerra. A solução diplomática foi a inauguração da Ponte da Amizade, que ofereceu clima de cooperação e a perspectiva de exportação de produtos paraguaios para o Brasil (Idem, 2012c).

Intensas negociações resultaram na Ata do Iguaçu de 1966, a qual manifestava a disposição conjunta de estudos sobre o "aproveitamento dos recursos hidráulicos pertencentes em condomínio aos dois países, no trecho do Rio Paraná 'desde e 
Revista das Faculdades Integradas Vianna Júnior

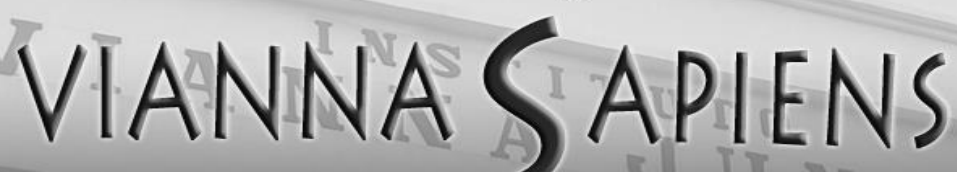

edição especial
iz de Fora - 2014

inclusive o Salto de Sete Quedas até a foz do Rio Iguaçu'.", conforme disposto no site da Itaipu Binacional (2012c).

Em 1973, após anos de estudos e buscas pelo ponto mais indicado para a construção da hidrelétrica, "brasileiros e paraguaios indicaram um trecho do rio conhecido como Itaipu, que, em tupi, quer dizer 'a pedra que canta'." (ITAIPU BINACIONAL, 2012c). Neste local havia uma ilha, logo após uma curva acentuada do rio, na qual a correnteza sob os barrancos próximos da confluência com o Rio Iguaçu indicavam um rendimento energético extraordinário. No dia 26 de abril de 1973, Brasil e Paraguai assinaram o Tratado de Itaipu, que legalizava o aproveitamento hidrelétrico do Rio Paraná pelos dois países. Em maio de 1974, a entidade binacional Itaipu foi formada a fim de gerenciar a construção da usina. A construção, segundo consta no site da Itaipu Binacional (2012c), previa o alagamento de grande parte da área em torno do Rio Paraná, desde o Salto das Sete Quedas em Guaíra até a foz do Rio Iguaçu. O governo brasileiro ficou responsável pela obtenção dos recursos para a obra, que foi obtido através de financiamento em instituições privadas e bancos estatais estrangeiros. Esta dívida terminará de ser paga em 2023.

Em meados de 1974, com a chegada das primeiras máquinas, a obra iniciouse. Foram construídas, segundo o site da Itaipu Binacional (2012c), as primeiras edificações, compostas por escritórios, almoxarifado, refeitório, alojamentos e posto de combustíveis. Mais de nove mil moradias foram construídas nos quatro anos seguintes, incluindo um hospital para atendimento aos trabalhadores. Em dez anos, a população de Foz do Iguaçu saltou de 20 mil habitantes para mais de 101 mil habitantes.

A primeira etapa para a construção da usina hidrelétrica foi desviar o leito do curso original do Rio Paraná, do qual foram removidos 55 milhões de metros cúbicos de terra e rocha para a escavação do desvio de dois quilômetros de extensão, 150 metros de largura e 90 metros de profundidade, originando um novo canal de passagem das águas, a fim de que um trecho do rio fosse secado para ali ser construída a barragem principal em concreto. Em outubro de 1978, com o desvio 
Revista das Faculdades Integradas Vianna Júnior

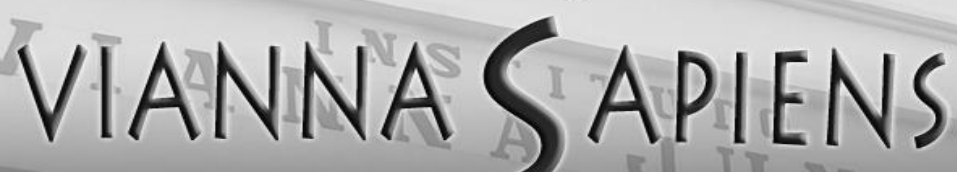

edição especial

concluído, 58 toneladas de dinamite explodiram "as duas ensecadeiras que protegiam a construção do novo curso", conforme disposto no site da Itaipu Binacional (2012c).

Desde o período em que o Tratado de Itaipu foi assinado, a Argentina temeu que a construção da usina pudesse prejudicar seus "direitos e interesses sobre as águas do Rio Paraná." O impasse foi resolvido com a assinatura do Acordo Tripartite, entre Brasil, Argentina e Paraguai, em outubro de 1979, o qual determinava regras para o aproveitamento dos recursos hidráulicos no trecho do rio, estabelecia os níveis do rio e as variações permitidas para os empreendimentos hidrelétricos na bacia comum aos três países (ITAIPU BINACIONAL, 2012c).

Com o desvio do rio concluído, iniciou-se a etapa de construção da barragem da Hidrelétrica, na qual foram utilizados mais de 12 milhões de metros cúbicos de concreto, sendo que em um único dia cerca de sete mil metros cúbicos de concreto foi utilizado por hora, o equivalente a um prédio de dez andares por hora ou 24 edifícios em um dia. Quatro rodovias do porte da Transamazônica poderiam ter sido construídas com todo o concreto utilizado na obra, segundo o site da Itaipu Binacional (2012c).

Em toda obra foram utilizados mais de 20 mil caminhões e 6.600 vagões ferroviários para transporte de materiais. Cerca de cinco mil pessoas eram contratadas por mês, devido a grande rotatividade de mão de obra. Em um único mês cerca de 40 mil pessoas trabalhavam diretamente nas obras (Idem,2012c).

O maior desafio, com a construção da barragem quase concluída, foi a montagem das unidades geradoras e o transporte de peças dos fabricantes até a usina. As primeiras turbinas, com 300 toneladas, levaram cerca de 3 meses para chegarem ao destino. Com a agilidade nos transportes, o recorde foi de 26 dias de viagem, conforme o site da Itaipu Binacional (2012c).

Após a conclusão da barragem em outubro de 1982, iniciaram-se os trabalhos para o "fechamento das comportas do canal de desvio, para a formação do reservatório da usina" (ITAIPU BINACIONAL, 2012c). Mais de 36 mil animais que viviam na área a ser inundada foram salvos. Uma pequena área não inundada foi 
transformada em reserva ecológica $O$ reservatório de 135 mil hectares foi formado em 14 dias, devido às fortes chuvas. Esta área compreende quatro vezes o tamanho da Baía da Guanabarra.

A formação do reservatório interferiu na vida de milhares de pessoas que habitavam às margens do Rio Paraná, desde Guaíra até Foz do Iguaçu. Devido ao fechamento das comportas, os moradores de Foz do Iguaçu viam o rio esvaziar, os moradores de Guaíra lamentavam o alagamento das Sete Quedas. Foram alagadas 8.519 propriedades urbanas e rurais na margem brasileira, sendo os donos indenizados.

Conforme informações apresentadas no site da Itaipu Binacional, (2012c):

\begin{abstract}
A 5 de novembro de 1982, com o reservatório já formado, os presidentes do Brasil, João Figueiredo, e do Paraguai, Alfredo Stroessner, acionam o mecanismo que levanta automaticamente as 14 comportas do vertedouro, liberam a água represada do Rio Paraná e, assim, inauguram oficialmente a maior hidrelétrica do mundo, após mais de 50 mil horas de trabalho.
\end{abstract}

O custo da usina é de aproximadamente US\$ 1.000 (mil dólares) por quilowatts instalados, ou cerca de US\$14 bilhões (quatorze bilhões de dólares). Em maio de 1984 a primeira das 20 unidades geradoras entrou em operação, sendo que em março de 1985 a energia começou a ser comercializada. Em maio de 2007, 33 anos após a assinatura do Tratado de Itaipu, as duas últimas unidades geradoras entraram em operação. As 20 unidades em atividade podem atingir a geração de até 100 bilhões de quilowatts-hora em condições climáticas favoráveis e chuvas em níveis normais (ITAIPU BINACIONAL, 2012c).

Os municípios brasileiros diretamente atingidos pelo alagamento foram Mundo Novo no Mato Grosso do Sul, Guaíra, Marechal Cândido Rondon, Santa Helena, São Miguel do Iguaçu, Medianeira, Santa Terezinha de Itaipu, Diamante D’Oeste, Terra Roxa e Foz do Iguaçu, todos do Paraná. Com os processos de emancipação política, Mercedes, Pato Bragado, Entre Rios do Oeste, São José das Palmeiras e Itaipulândia integraram-se ao rol dos municípios atingidos (CONSELHO DE DESENVOLVIMENTO DOS MUNICÍPIOS LINDEIROS AO LAGO DE ITAIPU, 2012). 
De acordo com o Anexo C do Tratado de Itaipu (2012b), item III.4, a entidade Itaipu Binacional deve o pagamento de royalties aos dois países no valor equivalente a "[...] seiscentos e cinquenta dólares dos Estados Unidos da América por gigawatthora, gerado e medido na central elétrica. Esse montante não poderá ser inferior, anualmente, a dezoito milhões de dólares [...]", sendo este pagamento realizado mensalmente. O acordo deverá ser revisto em 2023 quando o Tratado completa cinquenta anos, levando em consideração "[...] o grau de amortização das dívidas contraídas pela ITAIPU para a construção do aproveitamento e a relação entre as potências contratadas pelas entidades de ambos os países." (VI, Anexo C, Tratado de Itaipu, 2012b).

No Brasil, os royalties são repassados ao Tesouro Nacional e distribuídos, desde 1991 , da seguinte forma: $45 \%$ dos recursos para os municípios, $45 \%$ para os estados e 10\% para os órgãos federais, sendo estes: Ministério do Meio Ambiente, Ministério de Minas e Energia e Fundo Nacional de Desenvolvimento Científico e Tecnológico - FNDCT (ITAIPU BINACIONAL, 2012a).

Dos $45 \%$ municipais e $45 \%$ estaduais, $85 \%$ são destinados aos municípios e estados diretamente atingidos, denominados lindeiros e 15\% aos indiretamente atingidos, localizados a montante (acima) da Usina de Itaipu (BRASIL, Lei 9.984/2000, 2012e, art. 1 e 3). O rateio do recurso entre os municípios lindeiros é determinado segundo o ganho da geração de energia, pela vazão e, principalmente, em virtude da área inundada pelo Lago de Itaipu, variando mensalmente conforme a geração total de energia (ITAIPU BINACIONAL, 2012a). Assim, quanto maior a área inundada maior é o valor de royalties recebido pelo município.

A Tabela 1 demonstra a área alagada em cada um dos municípios lindeiros paranaenses ocasionados pela construção da usina hidrelétrica de Itaipu, conforme o site da Itaipu Binacional (2012a). Esta área é utilizada para o cálculo da distribuição dos royalties a cada um dos municípios. Consta também das compensações financeiras recebidas por cada um dos municípios lindeiros em 2011. Conforme o parágrafo único do artigo 26 do Decreto № 1 de 1991, os municípios que 
Revista das Faculdades Integradas Vianna Júnior

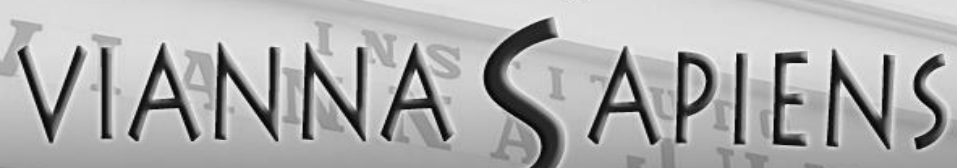

edição especial
iz de Fora - 2014

recebem compensações financeiras da Itaipu Binacional são proibidos da aplicação destes no "pagamento de dívidas e no quadro permanente de pessoal".

Tabela 1: Área alagada e recursos recebidos pelos municípios lindeiros ao lago de Itaipu

\begin{tabular}{l|c|c|r}
\hline \multicolumn{1}{c|}{ Municípios lindeiros } & Área alagada $\left(\mathbf{K m}^{2}\right)$ & $\begin{array}{c}\text { \% do total da área } \\
\text { alagada }\end{array}$ & $\begin{array}{c}\text { Royalties recebidos em } \\
\mathbf{2 0 1 1}\end{array}$ \\
\hline Diamante do Oeste & 5,62 & 0,54 & $758.657,87$ \\
\hline Entre Rios do Oeste & 32,90 & 3,18 & $4.438 .354,70$ \\
\hline Foz do Iguaçu & 201,84 & 19,50 & $27.229 .320,10$ \\
\hline Guaíra & 51,01 & 4,93 & $6.876 .592,36$ \\
\hline Itaipulândia & 179,73 & 17,37 & $24.246 .367,54$ \\
\hline Marechal Cândido Rondon & 56,04 & 5,42 & $156.042,50$ \\
\hline Medianeira & 1,16 & 0,11 & $2.606 .352,10$ \\
\hline Mercedes & 19,32 & 1,87 & $5.509 .435,68$ \\
\hline Missal & 40,07 & 3,87 & $6.349 .950,05$ \\
\hline Pato Bragado & 47,07 & 4,55 & $35.582 .384,14$ \\
\hline Santa Helena & 263,76 & 25,49 & $5.652 .494,30$ \\
\hline Santa Terezinha de Itaipu & 41,90 & 4,05 & $261.714,52$ \\
\hline São José das Palmeiras & 1,94 & 0,19 & $12.460 .886,02$ \\
\hline São Miguel do Iguaçu & 90,91 & 8,78 & $213.148,94$ \\
\hline Terra Roxa & 1,58 & 0,15 & \\
\hline
\end{tabular}

Fonte: Adaptado de Itaipu Binacional, 2012a.

\subsection{Análise das receitas}

Com base nos Relatórios Resumidos da Execução Orçamentária do exercício de 2011, disponíveis no site do Tesouro Nacional, são analisadas as receitas dos municípios lindeiros paranaenses. De acordo com as teorias contábeis da administração pública, as receitas podem ser de origem municipal, compreendendo as receitas tributárias, de contribuição, patrimonial, agropecuária, industrial e de serviços. São originárias também de transferências correntes dos governos estadual e federal, de outras receitas, como multas e juros da dívida, além das receitas de capital originárias de alienações de bens, operações de crédito, dentre outras. As compensações financeiras, ou royalties pertencem ao grupo das receitas patrimoniais, que para fins deste artigo são apresentadas separadamente.

O Gráfico 1 demonstra as origens das receitas de 2011 dos municípios lindeiros. Marechal Cândido Rondon, Foz do Iguaçu e Medianeira foram os 
municípios que tiveram mais de $20 \%$ (vinte por cento) das receitas oriundas de bases municipais, como IPTU (Imposto Predial Territorial Urbano) e ISSQN (Imposto Sobre Serviços de Qualquer Natureza), dentre outras.

Muitos municípios são dependentes dos recursos de transferências correntes, como São José das Palmeiras e Diamante D'Oeste, que do total de receitas realizadas, $88,22 \%$ (oitenta e oito vírgula vinte e dois por cento) e 83,38\% (oitenta e três vírgula trinta e oito por cento), respectivamente, foram originárias destas transferências.

Para alguns municípios, como Itaipulândia, Santa Helena e Pato Bragado, os royalties da Itaipu Binacional representaram 57,88\% (cinquenta e sete vírgula oitenta e oito por cento), $48,26 \%$ (quarenta e oito vírgula vinte e seis por cento) e $32,52 \%$ (trinta e dois vírgula cinquenta e dois por cento) de todas as receitas arrecadadas no período. Isto demonstra uma séria dependência de um recurso que, em um futuro próximo, deixará de ser recebido. Por serem municípios que tiveram uma grande área alagada, com grandes prejuízos econômicos ocasionados, os royalties são recursos repassados justamente para compensar estes prejuízos.

Para outros municípios, como Medianeira, Terra Roxa e São José das Palmeiras, as compensações financeiras compreenderam menos de $3 \%$ (três por cento) de todas as receitas realizadas em 2011. É importante ressaltar que estes municípios tiveram uma pequena área alagada. Os prejuízos ocasionados devido à construção da Usina Hidrelétrica para estes municípios foram irrisórios se comparados a outros. São municípios que, ao deixarem de receber os royalties, terão um impacto menor nos orçamentos anuais. 
Revista das Faculdades Integradas Vianna Júnior

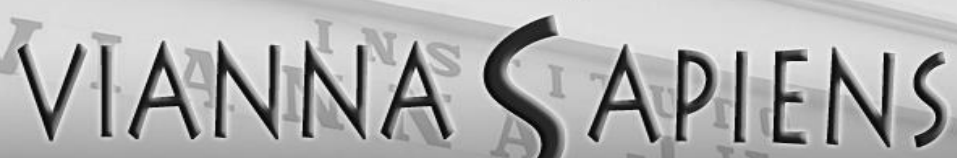

edição especial Juiz de Fora- 2014

Gráfico 1: Origens das receitas dos municípios lindeiros

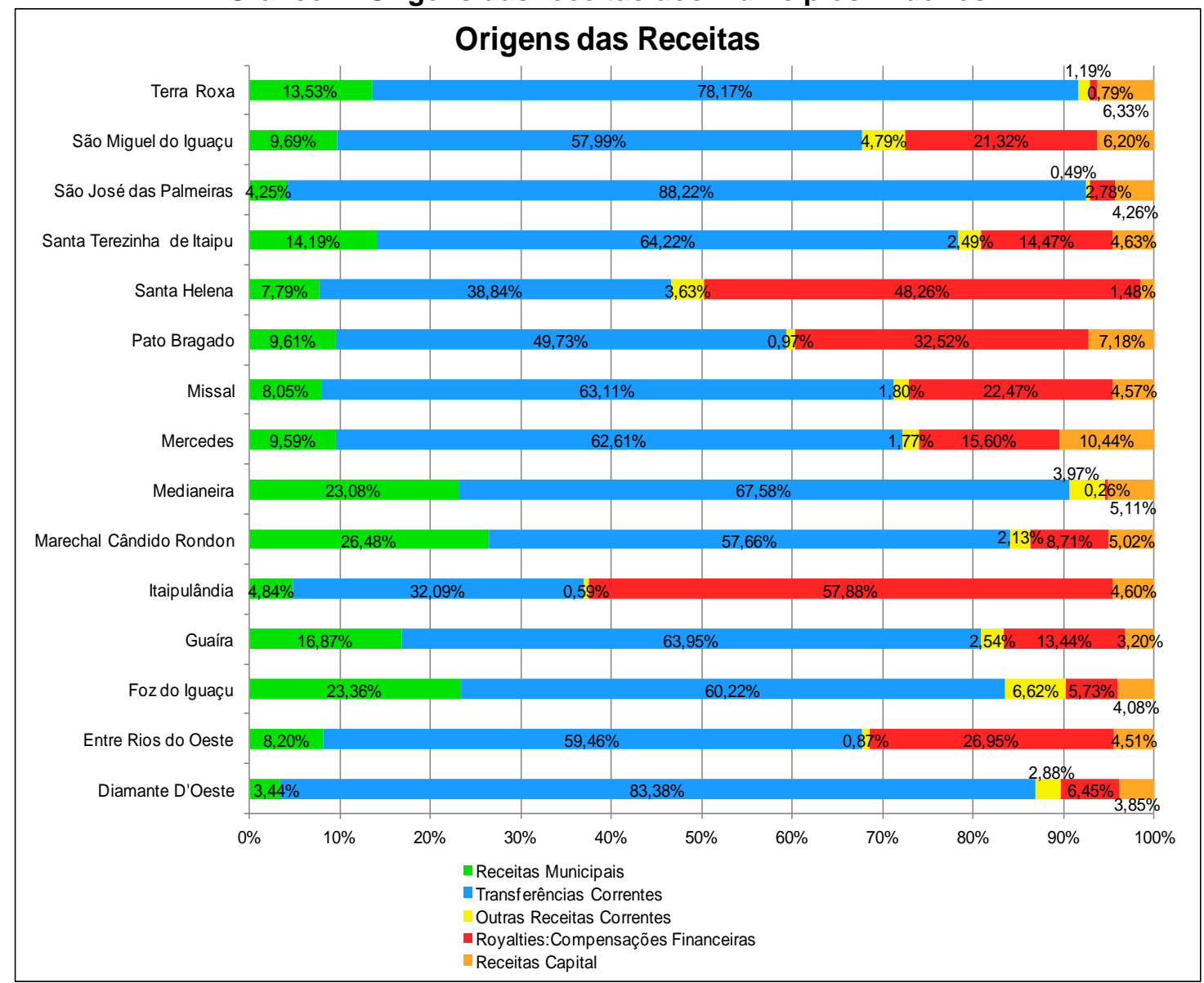

Fonte: Elaborado com base nos relatórios de 2011 publicados pelos municípios lindeiros.

O município de Foz do Iguaçu, apesar de ter tido uma das maiores áreas alagadas e ter recebido um montante elevado de compensações financeiras, este recurso representa apenas 5,73\% (cinco vírgula setenta e três por cento) de todas as receitas arrecadadas no período. Isto demonstra não haver dependência do recurso limitado, sendo um município que provavelmente investiu em ações que, de certa forma, compensaram os prejuízos e estão apresentando retornos financeiros de formas diferenciadas. 


\subsection{Análise das despesas}

De acordo com as teorias contábeis, as despesas são classificadas em correntes e de capital. Através da análise dos demonstrativos contábeis dos municípios lindeiros paranaenses, é possível identificar em que tipo de despesas foram aplicados os recursos financeiros.

Conforme expôs Silva, 2007, os municípios que mais se desenvolveram, foram aqueles que investiram recursos em infraestrutura, ou seja, em despesas de capital. Nesta perspectiva, segundo a Tabela 2, os municípios que mais realizaram investimentos em despesas de capital, proporcionalmente ao total de despesas executadas em 2011, foram Mercedes, Santa Helena e Medianeira.

O município de Medianeira aplicou mais de $\mathrm{R} \$ 12$ milhões (doze milhões de reais) em despesas de capital, sendo que recebeu pouco mais de $\mathrm{R} \$ 150$ mil (cento e cinquenta mil reais) de compensações financeiras.

Já o município de Itaipulândia recebeu em 2011 mais de $\mathrm{R} \$ 24$ milhões (vinte e quatro milhões de reais) de royalties, porém aplicou pouco mais de $R \$ 7$ milhões (sete milhões de reais) em despesas de capital. Estes investimentos não foram realizados unicamente com recursos de compensações financeiras, pois as receitas de capital são utilizadas exclusivamente para despesas de capital. 
Revista das Faculdades Integradas Vianna Júnior

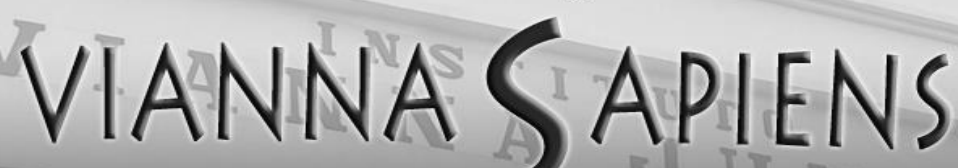

uiz de Fora - 2014

Tabela 2: Composição das despesas executadas no exercício de 2011

\begin{tabular}{l|c|c|c|r}
\hline $\begin{array}{c}\text { Municípios lindeiros } \\
\text { paranaenses }\end{array}$ & $\begin{array}{c}\text { Despesas } \\
\text { Correntes }\end{array}$ & $\begin{array}{c}\text { Despesas } \\
\text { Correntes em } \\
\%\end{array}$ & $\begin{array}{c}\text { Despesas de } \\
\text { Capital e Intra- } \\
\text { Orçamentárias }\end{array}$ & $\begin{array}{c}\text { Despesas } \\
\text { de Capital } \\
\text { em \% }\end{array}$ \\
\hline Diamante D'Oeste & $10.825 .509,76$ & 97,14 & $318.317,10$ & 2,86 \\
\hline Entre Rios do Oeste & $14.622 .596,00$ & 92,78 & $1.138 .688,38$ & 7,22 \\
\hline Foz do Iguaçu & $380.220 .305,05$ & 83,50 & $75.153 .755,31$ & 16,50 \\
\hline Guaíra & $45.426 .680,82$ & 91,62 & $4.154 .738,85$ & 8,38 \\
\hline Itaipulândia & $33.575 .955,83$ & 81,21 & $7.767 .791,62$ & 18,79 \\
\hline Marechal Cândido Rondon & $71.247 .853,32$ & 81,27 & $16.424 .677,21$ & 18,73 \\
\hline Medianeira & $46.949 .499,54$ & 79,48 & $12.119 .485,00$ & 20,52 \\
\hline Mercedes & $12.707 .005,63$ & 78,52 & $3.475 .687,04$ & 21,48 \\
\hline Missal & $21.422 .880,76$ & 89,34 & $2.557 .453,28$ & 10,66 \\
\hline Pato Bragado & $16.073 .521,70$ & 82,75 & $3.349 .502,61$ & 17,25 \\
\hline Santa Helena & $65.851 .873,07$ & 79,26 & $17.228 .024,34$ & 20,74 \\
\hline Santa Terezinha de Itaipu & $34.489 .679,53$ & 92,06 & $2.976 .502,07$ & 7,94 \\
\hline São José das Palmeiras & $7.881 .420,47$ & 88,72 & $1.002 .062,74$ & 11,28 \\
\hline São Miguel do Iguaçu & $47.660 .478,58$ & 88,55 & $6.161 .197,02$ & 11,45 \\
\hline Terra Roxa & $20.513 .191,03$ & 80,52 & $4.963 .193,58$ & 19,48 \\
\hline \multicolumn{2}{|c|}{ Fona } &
\end{tabular}

Fonte: Elaborado com base nos relatórios de 2011 publicados pelos municípios lindeiros.

Neste contexto, pode-se visualizar o descompasso da aplicação das compensações financeiras. Na medida em que há municípios que recebem poucos recursos de royalties e preocupam-se na aplicação dos mesmos em despesas que podem proporcionar o desenvolvimento econômico e social do município, existem outros que recebem muito mais, porém não aplicam tantos recursos para esta finalidade.

\subsection{Prováveis impactos nos orçamentos dos municípios lindeiros}

Sabendo-se o quanto os royalties representam do total da arrecadação de um município, é possível perceber o impacto que a falta deste recurso pode ocasionar no orçamento anual. Caso as compensações financeiras deixem de ser repassadas a partir de 2023, muitos municípios lindeiros sofrerão com a redução dos recursos disponíveis nas gestões públicas.

Conforme pode ser visualizado na Tabela 3, os municípios de Itaipulândia, Santa Helena, Pato Bragado e Entre Rios do Oeste são os que mais terão um impacto negativo nos orçamentos públicos, devido a maior proporção de recursos 
em relação ao orçamento total. Apesar de Foz do Iguaçu receber um montante elevado de royalties, este recurso representou um percentual pequeno em relação a arrecadação total no ano de 2011.

Com base na população estimada em 2011, segundo IBGE (2012), é possível verificar o quanto as compensações financeiras representaram para cada munícipe residente em cada um dos municípios lindeiros. Através da Tabela 3, identificou-se que nos municípios de Medianeira, Terra Roxa e São José das Palmeiras, os royalties representaram $R \$ 3,71$ (três reais e setenta e um centavos), $R \$ 12,69$ (doze reais e sessenta e nove centavos) e $R \$ 68,69$ (sessenta e oito reais e sessenta e nove centavos), respectivamente, para cada munícipe anualmente. Através de incentivos comerciais, industriais ou agropecuários, por exemplo, estes municípios podem obter um retorno financeiro até mesmo superior ao que os royalties representam atualmente.

Tabela 3: Representação dos royalties sobre o orçamento e royalties per capita

\begin{tabular}{|c|c|c|c|c|}
\hline $\begin{array}{c}\text { Municípios que fazem } \\
\text { parte da AMOP }\end{array}$ & Royalties 2011 & $\begin{array}{c}\% \text { Royalties/ } \\
\text { Receitas Totais }\end{array}$ & $\begin{array}{c}\text { População } \\
\text { Estimada } 2011\end{array}$ & $\begin{array}{l}\text { R\$ Royalties/ } \\
\text { População }\end{array}$ \\
\hline Diamante D'Oeste & $758.657,87$ & 6,45 & 5.039 & 150,56 \\
\hline Entre Rios do Oeste & $4.438 .354,70$ & 26,95 & 3.972 & $1.117,41$ \\
\hline Foz do Iguaçu & $27.229 .320,10$ & 5,73 & 255.900 & 106,41 \\
\hline Guaíra & $6.876 .592,36$ & 13,44 & 30.861 & 222,82 \\
\hline Itaipulândia & $24.246 .367,54$ & 57,88 & 9.195 & $2.636,91$ \\
\hline Marechal Cândido Rondon & $7.560 .042,50$ & 8,71 & 47.266 & 159,95 \\
\hline Medianeira & $156.489,10$ & 0,26 & 42.124 & 3,71 \\
\hline Mercedes & $2.606 .352,96$ & 15,60 & 5.080 & 513,06 \\
\hline Missal & $5.509 .435,68$ & 22,47 & 10.478 & 525,81 \\
\hline Pato Bragado & $6.349 .950,05$ & 32,52 & 4.882 & $1.300,69$ \\
\hline Santa Helena & $35.582 .384,14$ & 48,26 & 23.638 & $1.505,30$ \\
\hline Santa Terezinha de Itaipu & $5.652 .494,30$ & 14,47 & 21.031 & 268,77 \\
\hline São José das Palmeiras & $261.714,52$ & 2,78 & 3.810 & 68,69 \\
\hline São Miguel do Iguaçu & $12.460 .886,02$ & 21,32 & 25.872 & 481,64 \\
\hline Terra Roxa & $213.148,94$ & 0,79 & 16.795 & 12,69 \\
\hline
\end{tabular}

Fonte: Elaborado com base nos relatórios de 2011 publicados pelos municípios lindeiros.

Já os municípios de Itaipulândia, Santa Helena, Pato Bragado e Entre Rios do Oeste, ao deixarem de receber as compensações financeiras, terão um impacto maior em seus orçamentos. Na análise de royalties por habitante, Itaipulândia 
recebeu o equivalente a $R \$ 2.636,91$ (dois mil, seiscentos e trinta e seis reais e noventa e um centavos) para cada munícipe. Caso este município não mais receber esses recursos, haverá uma grande defasagem nos orçamentos anuais, comprometendo toda manutenção da máquina pública.

Os impactos serão sentidos de forma diferenciada em cada um dos municípios lindeiros. É necessário que estes se utilizem dos royalties de forma a compensar os prejuízos causados com a construção da Usina Hidrelétrica de Itaipu através de investimentos que tragam retornos financeiros e econômicos, para que não haja uma dependência. Porém, devem ser investimentos de pouca manutenção, conforme explicitou Oliveira (2008).

\section{CONCLUSÕES}

O objetivo desta pesquisa foi analisar a composição das receitas e despesas dos municípios paranaenses lindeiros ao lago de Itaipu, com a finalidade de verificar o possível impacto que possa ocasionar nos orçamentos destes municípios quando deixarem de receber os royalties da Itaipu Binacional.

Em resposta à questão norteadora desta pesquisa concluiu-se que os impactos que os municípios sofrerão ao deixarem de receber as compensações serão sentidos de formas diferenciadas. Proporcionalmente ao total de arrecadação, para alguns municípios as compensações financeiras corresponderam a uma fatia maior de recursos do que para outros. Enquanto há municípios que recebem poucos royalties e investem muito em infraestrutura, há outros que recebem mais, mas investem pouco nestas ações.

Para alguns municípios, a diferença será pequena, passível de recuperação através de investimentos ou fortalecimentos de setores que tragam retornos financeiros, econômicos e sociais. Outros municípios, se deixarem de receber os royalties, terão um impacto muito forte nas finanças municipais, o que pode prejudicar o desenvolvimento econômico e social. É necessário que estes 
municípios busquem soluções urgentemente, criando condições para investimentos em setores que possam trazer retornos no futuro de forma que a população dos mesmos não seja prejudicada pela falta de recursos.

Já se passaram mais de vinte anos de recebimento das compensações financeiras, restando apenas cerca de dez anos até a revisão do tratado. É necessário que os municípios lindeiros invistam em setores que tragam, de formas diferenciadas, mais recursos financeiros e aprimorem o desenvolvimento econômico e social.

\title{
ANALYSIS OF REVENUES BREAKDOWN OF MUNICIPALITIES BORDERING LAKE ITAIPU BINATIONAL IN PARANÁ
}

\begin{abstract}
The objective of this research is to analyze the composition of revenue and expenditure of the Itaipu lake bordering municipalities of Paraná, in order to ascertain the possible impact that may occur in these municipalities budget from the year they cease to receive royalties from Itaipu. The methodology is characterized as a multicase study, using the literature and documents, and an exploratory study with quantitative and qualitative approaches. The theoretical basis comes to matters pertaining to the analysis of the finances of the surrounding cities. As for the results, it was found that the larger the affected area, the greater the receipt of royalties. Proportion to the total fund for some municipalities' financial compensation accounted for a larger share of resources than others. While there are few municipalities that receive royalties and invest heavily in infrastructure, there are others who receive more but invest little in these actions. It was concluded that the impacts will be felt in different ways in each of the municipalities. The time of receipt
\end{abstract}


of these funds until the revision of the treaty of Itaipu, is short, necessary investments in sectors that carry, in different ways, more financial resources and enhance the economic and social development being.

KEYWORDS: IMPACT. ROYALTIES. SURROUNDING CITIES.

\section{REFERÊNCIAS}

ANDRADE, Nilton de Aquino. Contabilidade pública na gestão municipal. São Paulo: Atlas, 2002.

ARAÚJO, Inaldo da Paixão Santos; ARRUDA, Daniel Gomes. Contabilidade pública: da teoria à prática. São Paulo: Saraiva, 2004.

BEM, Jorge Sebastião de; BATTI, Frederico Barbosa Bez. Uma abordagem regional das finanças municipais. Análise conjuntural. vol. 25, n. 7-8, p. 4, jul/ago 2003. Disponível em: < http://www.ipardes.gov.br/biblioteca/docs/bol 25 4b.pdf >. Acesso em: 04/2012.

BEUREN, Ilse Maria. Como elaborar trabalhos monográficos em contabilidade: teoria e prática. - 3. ed. - 5. reimpr. - São Paulo: Atlas, 2010.

BEZERRA FILHO, João Eudes. Contabilidade pública: teoria, técnica de elaboração de balanços e questões. 3. ed. Rio de Janeiro: Elsevier, 2008.

BRASIL. Lei no 4.320, de 17 de março de 1964. Estatuto Normas Gerais de Direito Financeiro para elaboração e controle dos orçamentos e balanços da União, dos Estados, dos Municípios e Distrito Federal. Disponível em: < http://www.planalto.gov.br/ccivil 03/Leis/L4320.htm > Acesso em: 04/2012a.

.Constituição da república federativa do Brasil de 1988. Disponível em: < http://www.planalto.gov.br/ccivil 03/constituicao/constituicaocompilado.htm > Acesso em: 04/2012b.

.Decreto no 1, de 11 de Janeiro de 1991. Regulamenta o pagamento da compensação financeira instituída pela Lei nํ 7.990, de 28 de dezembro de 1989, e dá outras providências. Disponível em: < http://www.planalto.gov.br/ccivil 03/decreto/1990-1994/D0001.htm > Acesso em: 04/2012c. 
Lei complementar 101, de 04 de maio de 2000. Estabelece normas de finanças públicas voltadas para a responsabilidade na gestão fiscal e da outras providências. Disponível em: < http://www.planalto.gov.br/CCIVIL/Leis/LCP/Lcp101 > Acesso em: 04/2012d.

. Lei no 9.984, de 17 de julho de 2000. Dispõe sobre a criação da Agência Nacional de Águas - ANA, entidade federal de implementação da Política Nacional de Recursos Hídricos e de coordenação do Sistema Nacional de Gerenciamento de Recursos Hídricos, e dá outras providências. Disponível em: < http://www.planalto.gov.br/ccivil 03/leis/L9984.htm\#art29 > Acesso em: 04/2012e.

CONSELHO DE DESENVOLVIMENTO DOS MUNICÍPIOS LINDEIROS AO LAGO DE ITAIPU. Histórico do conselho de desenvolvimento dos municípios lindeiros ao lago de Itaipu. Disponível em: < http://www.lindeiros.org.br/lindeiros/paginas.php?idmat=918 >. Acesso em: 06/2012.

DANTON, Gian. Metodologia Científica. Virtualbooks. 2002. Disponível em: < http://www.virtualbooks.com.br >. Acesso em: 10/2012.

IBGE. Instituto Brasileiro de Geografia e Estatística. Cidades. Disponível em: < http://www.ibge.gov.br/cidadesat/index.php > Acesso em: 06/2012.

ITAIPU BINACIONAL. Royalties. Disponível em: < http://www.itaipu.gov.br/responsabilidade/royalties > Acesso em: 02/2012a.

. Tratado de Itaipu e anexos. Disponível em: <

http://www.itaipu.gov.br/institucional/documentos-oficiais > Acesso em: 02/2012b.

A história da maior hidrelétrica do mundo. Disponível em: < http://www.itaipu.gov.br/nossa-historia > Acesso em: 05/ 2012c.

IWAKE, Shiguera. Análise das Modificações na Estrutura Orçamentária dos Municípios Lindeiros Recebedores de Royalties de ITAIPU. Diálogo Econômico. Paraná: CORECON, no 3, p. 24-25, Fevereiro. 2005. Disponível em: < http://www.coreconpr.org.br >. Acesso em: 02/ 2012.

JUND, Sergio. Administração, orçamento e contabilidade pública. 3. ed. Rio de Janeiro: Elsevier, 2008.

OLIVEIRA, Leoveraldo Curtarelli de. Economia, instituições e royallties: o caso dos municípios lindeiros ao lago de Itaipu Binacional no oeste paranaense. 2008.

Dissertação (mestrado em Desenvolvimento Regional e Agronegócio) - Toledo, Universidade Estadual do Oeste do Paraná. Disponível em: < http://tede.unioeste.br/tede/tde arquivos/2/TDE-2008-07-17T132449Z253/Publico/Leoveraldo\%20C\%20de\%20Oliveira.pdf >. Acesso em: 04/2012. 


\section{VIANNA SAPIENS}

edição especial

Juiz de Fora - 2014

RAUPP, Fabiano Maury; BEUREN, Ilse Maria. Metodologia da pesquisa aplicável às ciências sociais. In: BEUREN, Ilse Maria (Org.). Como elaborar trabalhos

monográficos em contabilidade: teoria e prática. 3. ed. 3. reimpr. São Paulo: Atlas, 2008. p. 76-97.

SILVA, Ludimila Lima da. A compensação financeira das usinas hidrelétricas como instrumento econômico de desenvolvimento social, econômico e ambiental. 2007. Dissertação (mestrado em Economia - Gestão Econômica do Meio Ambiente) Brasília, Departamento de Economia da Universidade de Brasília. Disponível em: < http://www.aneel.gov.br/biblioteca/trabalhos/trabalhos/Disserta\%C3\%A7\%C3\%A3o Ludimila.pdf >. Acesso em: 04/2012.

STERCHILE, Schirla Patricia Weber; SOUZA, Edson Belo Clemente. Apontamentos sobre a aplicação dos royalties da Itaipu Binacional e o processo de desenvolvimento. Revista brasileira de gestão e desenvolvimento regional. Taubaté, v. 4, № 2. maio/ago. 2008. ISSN 1809-239X. Disponível em: < http://www.rbgdr.net/022008/artigo1.pdf > . Acesso em: 02/2012.

TESOURO NACIONAL. Sistema de coleta de dados contábeis de estados e municípios - SISTN. <

https://www.tesouro.fazenda.gov.br/estados municipios/sistn.asp?complemento=cod Estado\%3D41\%26codMunicipio\%3D41*00001535*8*1\%26esfera\%3D1\#pesquisa $>$. Acesso em: 02/2012.

YIN R. Estudo de caso: planejamento e métodos. 2 ed. Porto Alegre: Bookman; 2001. 